\title{
Conversion of furfural to 2-methylfuran over CuNi catalysts supported on biobased carbon foams
}

Toni Varila*[a,b], Eveliina Mäkelä ${ }^{[c]}$, Riikka Kupila ${ }^{[a, b]}$, Henrik Romar ${ }^{[a]}$, Tao Hu${ }^{[a]}$ Reetta Karinen ${ }^{[\mathrm{c}]}$, Riikka L. Puurunen $^{[\mathrm{c}]}$ and Ulla Lassi ${ }^{[\mathrm{a}, \mathrm{b}]}$

a) Research Unit of Sustainable Chemistry, University of Oulu, P.O. Box 8000, 90014 Oulu, Finland

b) Kokkola University Consortium Chydenius, Applied Chemistry, University of Jyväskylä, P.O. Box 567, 67101 Kokkola, Finland

c) Department of Chemical and Metallurgical Engineering, Aalto University School of Chemical Engineering, P.O. Box 16100, 00076 AALTO, Finland

*Corresbonding author: toni.varila@chydenius.fi

\begin{abstract}
In this study, carbon foams prepared from the by-products of the Finnish forest industry, such as tannic acid and pine bark extracts, were examined as supports for $5 / 5 \% \mathrm{Cu} / \mathrm{Ni}$ catalysts in the hydrotreatment of furfural to 2-methylfuran (MF). Experiments were conducted in a batch reactor at 503 $\mathrm{K}$ and 40 bar $\mathrm{H}_{2}$. Prior to metal impregnation, the carbon foam from tannic acid was activated with steam (S1), and the carbon foam from pine bark extracts was activated with $\mathrm{ZnCl}_{2}$ (S2) and washed with acids $\left(\mathrm{HNO}_{3}\right.$ or $\left.\mathrm{H}_{2} \mathrm{SO}_{4}\right)$. For comparison, a spruce-based activated carbon (AC) catalyst and two commercial AC catalysts as references were investigated. Compressive strength of the foam S2 was 30 times greater than that of S1. The highest MF selectivity of the foam-supported catalysts was $48 \%$ (S2, washed with $\mathrm{HNO}_{3}$ ) at a conversion of $91 \%$. According to the results, carbon foams prepared from pine bark extracts can be applied as catalyst supports.
\end{abstract}

Keywords: Biobased foams, carbon, mechanical strength, furfural, $\mathrm{Cu} / \mathrm{Ni}$ catalyst, 2-methylfuran. 


\section{Introduction}

Owing to the increase in the demand for chemicals and liquid fuels, which are primarily prepared from depleting fossil fuel sources, the growing society requires sustainable and renewable resources to produce value-added chemicals and liquid fuels $[1,2]$. Biomass has been widely investigated for decades, and it has proven to be a good source of energy and raw material for chemicals and fuels due to its consistency, renewability, structure, and easy availability [3]. Biomass can be applied in several industrial and chemical processes, such as pyrolysis, gasification, fermentation, and extraction, to produce heat, electricity, and biobased materials, such as ethanol and furfural derivatives. Developing countries produce lignocellulosic feedstocks, which are mainly used as energy for industrial boilers [4]. In Finland, lignocellulosic feedstock, which is produced by the forest industry, is also used as an energy source,[5] as well as in the pulping process, and it can be further developed in biorefineries to produce other valueadded products, e.g., 2-methylfuran (MF) and its derivatives [6]. As a side product, bark and lignin are produced in a large amount, which are mainly considered as waste or low-value products [7].

Furfural is known as a platform chemical, which is obtained from lignocellulosic biomass by the hydrolysis and dehydration of hemicellulose [8]. Hydrotreatment is a typical process for the upgrading of furanic components; the conversion can be performed in either the gas or liquid phase [8,9]. MF is one of the most important products obtained from the hydrotreatment of furfural, which can be used as a solvent or biofuel when blended with gasoline [9]. MF demonstrates the potential to replace fossil-based components in gasoline due to its beneficial fuel characteristics, e.g., high octane number and low solubility in water (research octane number of 131, $7 \mathrm{~g} \mathrm{~L}^{-1}$ ) [10]. Recent studies have reported high MF yields [11-14]. For example, Fu et al. [11] have reported an MF yield of 92\% over a 10-10\% CuNi catalyst on an $\mathrm{Al}_{2} \mathrm{O}_{3}$ support, with a furfural conversion of $100 \%$, at $483 \mathrm{~K}$ using formic acid as the hydrogen donor. 
Furanic compounds, such as furfural, can be adsorbed on a metal either via the furan ring or via the oxygenated side chain or both. The adsorption mode of furfural depends on the nature of the metal. Three typical adsorption modes are as follows: $\eta^{1}-(\mathrm{O})$ adsorption mode via the aldehyde functionality, $\eta^{2}-(\mathrm{C}, \mathrm{O})$ adsorption mode, in which the furan ring is adsorbed on the metal with the $\mathrm{C}$ atom but also with the $\mathrm{O}$ atom of the carbonyl group, and $\eta^{1}-(\mathrm{C})$ acyl adsorption mode, which is converted from $\eta^{2}-(\mathrm{C}, \mathrm{O})$ adsorption at high temperatures $[15,16]$. Furfural exhibits a stronger interaction with $\mathrm{Ni}$ (in contrast to $\mathrm{Cu}$ ), permitting the adsorption of the furan ring via the $\eta^{2}-(\mathrm{C}, \mathrm{O})$ adsorption mode. In case of $\mathrm{Cu}$, the $\mathrm{Cu}(111)$ surface, in particular, exhibits a strong repulsion for the furan ring; thus, the typical adsorption mode is $\eta^{1}-(\mathrm{O})$ [16].

Shi [17] has conducted a density functional theory (DFT) study and reported that MF can be formed by four competitive routes. The attack of carbon from the $\mathrm{C}=\mathrm{O}$ group by hydrogen affords an alkoxy intermediate or a 2-furanyl(hydroxy)methyl intermediate. In addition, direct $\mathrm{C}=\mathrm{O}$ and $\mathrm{C}-\mathrm{H}$ dissociation routes were presented. Among these pathways, the formation of the alkoxy intermediate species was the rate-determining step [17]. In general, the Cu catalyst favored the production of furfuryl alcohol (FA), MF, and pentanediols rather than decarbonylation and furan-ring hydrogenation products, such as 2methyltetrahydrofuran (MTHF) and THF. As the hydrogenation of the $\mathrm{C}=\mathrm{O}$ bond in FA was relatively less favorable, which is required to obtain MF $[10,16,18]$, the activity can be increased by utilizing a high reaction temperature, adding a second oxophilic metal to the catalyst to enhance the deoxygenation ability, or increasing the Lewis acidity of the catalyst [16]. The presence of both $\mathrm{Cu}$ and $\mathrm{Cu}^{+}$in the catalyst is crucial. Metallic $\mathrm{Cu}$ was proposed to activate $\mathrm{H}_{2}$ and the $\mathrm{Cu}^{+}$species, which serve as a Lewis acid or as electrophilic sites polarizing the $\mathrm{C}=\mathrm{O}$ bond [19].

Owing to the higher hydrogenation activity of $\mathrm{Ni}$, the distribution of products obtained over a $\mathrm{Ni}$ catalyst is typically wider than obtained over a $\mathrm{Cu}$ catalyst. In addition to FA, MF, pentanediols, cyclopentanone, and cyclopentanol, tetrahydrofurfuryl alcohol (THFA), MTHF, THF, and furan can be obtained. Previously, Rodiansono et al. [20] have reported the formation of 1,4-pentanediols over Ni 
catalysts. THFA is formed by the nonselective hydrogenation over most of the Ni catalysts [16]. The MF selectivity can be improved by the application of bimetallic Ni catalysts; for example, the NiFe alloy can reduce the decarbonylation activity and improve the hydrogenolysis of the $\mathrm{C}-\mathrm{O}$ bond of $\mathrm{FA}$ by hindering the transformation of the $\eta^{2}-(\mathrm{C}, \mathrm{O})$ adsorption mode to the $\eta^{1}-(\mathrm{C})$ acyl adsorption mode [21]. Moreover, Yu et al. [22] have conducted a DFT study and proposed that the main adsorption mode is via the aldehyde functionality on the NiFe surfaces. A similar interaction also was observed on the $\mathrm{NiCu}(111)$ surface [15].

Activated carbons (ACs) are produced by thermal treatment or a combination of chemical and thermal treatment of carbon-rich sources such as lignite or of lignocellulosic materials in the case of biomass-based carbon. In AC production, coconut shells, peat, and wood chips or saw dust are typically used as biobased raw materials $[23,24]$. The porous structure, high specific surface area (SSA), and adsorption capacity of ACs are widely exploited in several industrial and municipal purification processes. ACs are mainly applied for wastewater treatment, gas cleaning processes, metal removal from waste streams, and as a catalyst [25-30]. Recently, AC has been used as a support material for transition metals, and its activity for the hydrotreatment of furfural has been investigated. For example, Fu et al. [12] have reported a high MF yield (91\%) after a reaction time of $8 \mathrm{~h}$ at $473 \mathrm{~K}$ (formic acid as the hydrogen donor) using the 10-10\% CuNi catalyst on AC. Date et al. [13] have reported an MF yield of 95\%, with almost complete conversion, after a reaction time of $5 \mathrm{~h}$ at $493 \mathrm{~K}\left(6.9 \mathrm{bar} \mathrm{H}_{2}\right.$ pressure $)$ over a $5 \%$ Ir/AC catalyst. Gong et al. [31] have reported the highest MF yield of almost 100\%, with 100\% furfural conversion, over a $\mathrm{Cu} / \mathrm{AC}$ catalysts at $440 \mathrm{~K}$ and $40 \mathrm{bar}_{2}$ after a reaction time of $4 \mathrm{~h}$.

One of the drawbacks of using ACs as a catalyst support material is their limited mechanical stability, especially abrasion strength [32,33]. Typically, briquetting or other techniques that can enhance the mechanical stability of ACs are required to avoid particle shattering and a high pressure drop in a fixedbed reactor [34,35]. Hence, widely investigated condensed tannin-based carbon foams [36-38] are promising support materials due to the possibility of tailoring the mechanical strength by hightemperature thermal treatment [39]. Thermal treatment (steam activation) typically produces a 
microporous material, whereas chemical activation (e.g., using $\mathrm{ZnCl}_{2}$ ) typically produces a mesoporous material [28].

Tannic-acid-based or pine-bark-extracts-based carbon foams (Fig. 1) can be produced using a combination of a phenolic substance (condensed or hydrolysable tannin), which are found in plants or in the wood bark structure, a cross-linker, catalyst, surfactant, and blowing agent. Physical properties, such as SSA, pore size distribution (PSD), mechanical strength, electrical and thermal conductivities, fire resistance, metal adsorption, and permeability, of tannin-based foams have been investigated previously [40-42]. However, to the best of our knowledge, the use of these foams as catalyst support materials has not been attempted previously.

In this study, the goal was to investigate the use of two activated carbon foams (ACF), which were produced from tannic acid and pine bark extracts, respectively, as catalyst supports for bimetallic $\mathrm{Cu} / \mathrm{Ni}$ $(5 / 5 \mathrm{w} \%)$ catalysts in the conversion of furfural to MF. As-prepared ACF were activated by physical and chemical activation methods. In addition, the SSA, PSD, and mechanical strength of these catalysts were investigated. Prior to metal addition, the activated support materials were further washed with $\mathrm{HNO}_{3}$ and

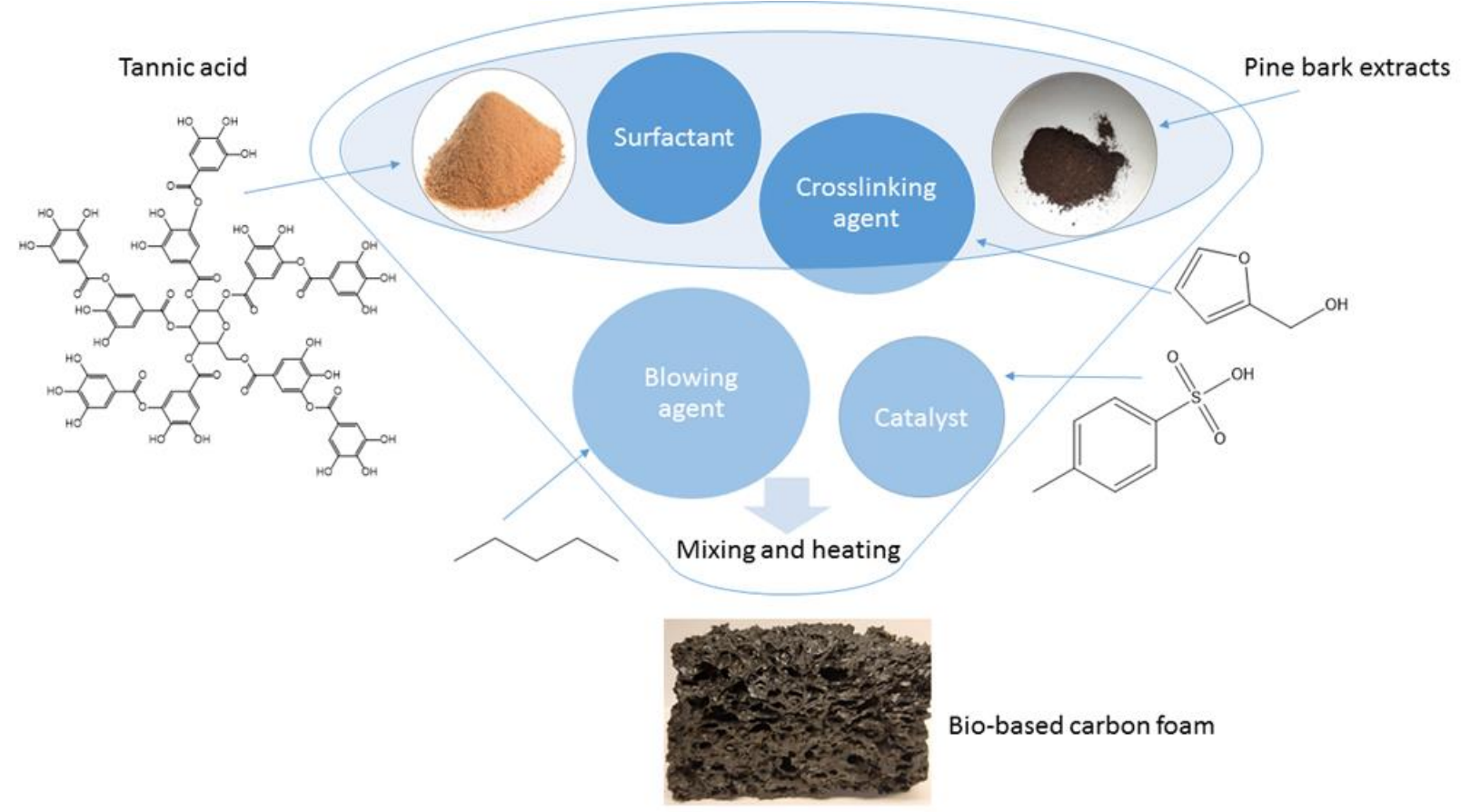


$\mathrm{H}_{2} \mathrm{SO}_{4}$ to modify their surface properties. The combination of $\mathrm{Cu}$ and $\mathrm{Ni}$ was selected as these metals were found to be beneficial for the hydrotreatment of furfural to produce MF $[11,12,43]$.

\section{Material and Methods}

For the first catalyst support material (S1), commercial tannic acid (95\%), FA (98\%), and surfactant (Tween 85) were purchased from Acros Organics. The acid catalyst p-toluenesulfonic acid monohydrate (PTSA, 99\%) for the foaming reaction and the blowing agent n-pentane (99.4\%) were purchased from Merck KGaA. For chemical activation, technical-grade $\mathrm{ZnCl}_{2}$ (97\%) was purchased from VWR Chemicals. Catalytic precursors of nickel(II) nitrate hexahydrate $(20.17 \mathrm{w} \% \mathrm{Ni}, 99 \%$ purity) and copper(II) nitrate hemi(pentahydrate) $(27.30 \mathrm{w} \% \mathrm{Cu}, 98 \%$ purity) were purchased from Merck KGaA and Alfa Aesar, respectively. For the second catalyst support material (S2), pine bark from northern Finland was used as the raw material. Pine bark was extracted using ETA 700 solution $(70 \mathrm{w} \%$ ethanol in a water disinfectant solution), which was purchased from ETRA Oy Finland. For the third catalyst support material (S3), fine spruce powder from northern Finland was used. For acid treatment, $\mathrm{HNO}_{3}(65 \mathrm{~m} \%)$, $\mathrm{HCl}(32 \mathrm{w} \%)$, and $\mathrm{H}_{2} \mathrm{SO}_{4}(96 \mathrm{w} \%$ ) were purchased from Merck KGaA. Commercial AC supports, i.e., steam-activated carbon (RB4C) and acid-washed carbon (RX3 extra), were obtained from Norit.

For batch reactor experiments, the below-listed chemicals were purchased from Sigma-Aldrich. FA (98\%), furan ( $\geq 99 \%)$, MF (99\%), THFA (99\%), MTHF (anhydrous, $\geq 99 \%), 2$-propanol ( $\geq 99.5 \%), 2$ butanol (99\%), 2-pentanol (98\%), cyclopentanol (99\%), 2-pentanone (99.5\%), and cyclopentanone $(\geq 99 \%)$ were used without further purification. Furfural $(99 \%)$ was distilled to a final molar purity of 99.8\%. The gases used for batch experiments were purchased from Oy AGA Ab. The purity of the hydrogen used for reactor experiments was 5.0, and the gases used in analytics were $\mathrm{H}_{2}$ (purity 5.0), He (purity 4.6), Ar (purity 5.0), synthetic air (purity 5.0), and $\mathrm{N}_{2}$ (purity 5.0). Two calibration gas mixtures were utilized. The first contained $40 \mathrm{~mol} \% \mathrm{~N}_{2}, 5 \mathrm{~mol} \% \mathrm{CH}_{4}, 10 \mathrm{~mol} \% \mathrm{C}_{2} \mathrm{H}_{6}, 5 \mathrm{~mol} \% \mathrm{C}_{2} \mathrm{H}_{4}, 10 \mathrm{~mol} \%$ $\mathrm{C}_{3} \mathrm{H}_{8}, 5 \mathrm{~mol} \% \mathrm{C}_{3} \mathrm{H}_{6}, 5 \mathrm{~mol} \% \mathrm{C}_{2} \mathrm{H}_{2}, 10 \mathrm{~mol} \% \mathrm{C}_{4} \mathrm{H}_{10}$, and $10 \mathrm{~mol} \%$ isobutane. The second calibration gas mixture contained 15 vol\% CO, 15 vol\% $\mathrm{CO}_{2}, 15$ vol\% $\mathrm{H}_{2}, 40$ vol\% $\mathrm{N}_{2}$, and 15 vol\% $\mathrm{CH}_{4}$. 


\subsection{Preparation of catalyst supports $S 1, S 2$, and $S 3$}

Supports S1 and S3: The commercial tannic acid mixture was used to prepare support 1 (S1). First, deionized water (9 g), furfuryl alcohol (14 g), and Tween 85 (2 g) were thoroughly mixed for $30 \mathrm{~s}$ in a 1L beaker. Second, tannic acid (30 g) was added to this liquid mixture and mixed with a mechanical stirrer (2000 rpm) for $5 \mathrm{~min}$. Third, pentane was added (4.5 g) to the homogenous solution, followed by the addition of PTSA $8 \mathrm{~g}, 65 \%$ solution), and it was rapidly stirred with a mechanical stirrer. Foaming occurred within a few seconds, and polymerization was highly exothermic. When the initial foam stopped increasing, the beaker was placed in an oven for $24 \mathrm{~h}$ at $373 \mathrm{~K}$ by natural convection to harden the foam.

Matured S1 was cut in pieces $(1 \mathrm{~cm} \times 1 \mathrm{~cm} \times 1 \mathrm{~cm})$ and placed in a stainless-steel tube, which was subsequently placed in a tubular fixed-bed reactor for activation. For support S1, steam activation was conducted at $1073 \mathrm{~K}$ using a ramp rate of $10 \mathrm{~K} \mathrm{~min}^{-1}$ and a holding time of $4 \mathrm{~h}$ at the target temperature. For support S3, spruce sawdust was activated by steam at $1073 \mathrm{~K}$ using a ramp rate of $6.5 \mathrm{~K} \mathrm{~min}^{-1}$ and a holding time of $2 \mathrm{~h}$. A water flow of $0.050 \mathrm{~mL} \mathrm{~min}^{-1}$ was utilized for both activation methods at the target temperature. Nitrogen gas was flushed through the reactor to avoid sample oxidation. After physical activation, S3 material was washed several times with hot water to remove impurities such as $\mathrm{Ca}, \mathrm{K}, \mathrm{Mg}$, $\mathrm{Na}$, and Fe. Next, the catalyst support material was sieved to obtain particle sizes of $100-425 \mu \mathrm{m}$ and further characterized and used for catalyst preparation.

Support S2: Pine bark extracts were used to prepare support 2 (S2). First, the bark was dried at room temperature, followed by crushing and sieving to obtain a particle size of less than $1 \mathrm{~mm}$. Second, the bark was extracted with EtOH: $\mathrm{H}_{2} \mathrm{O}(70: 30)$ at a bark:solvent ratio of 75:1 $\left(\mathrm{g} \mathrm{L}^{-1}\right)$. Extraction was carried out using a Soxhlet extractor for $2 \mathrm{~h}$ at an oil bath temperature of $\sim 383 \mathrm{~K}$. The bark extracts were dried at room temperature in a fume hood until the solvent was evaporated ( 2 days). Then, support S2 was prepared as follows. 
First, pine bark extracts ( $30 \mathrm{~g})$ were placed in a $400-\mathrm{mL}$ beaker, followed by melting on a hot plate at $373 \mathrm{~K}$ to enable the mixing of the extractives with a spatula. Second, deionized water $(9 \mathrm{~g})$, furfural alcohol (14 g), and Tween 85 (2 g) were added to this solution, and the mixture was thoroughly mixed for 5 min using a mechanical stirrer. Third, pentane $(4.5 \mathrm{~g})$ and PTSA (8 g, 65\% solution) were added and stirred for $10 \mathrm{~s}$. Foaming occurred within few minutes after placing the beaker in an oven at $373 \mathrm{~K}$. The foam was hardened for $24 \mathrm{~h}$ at this temperature before further use.

First, matured S2 was gently crushed in a mortar using a pestle for chemical activation. Technicalgrade $\mathrm{ZnCl}_{2}$ (40 g) was dissolved in $100-200 \mathrm{~mL}$ of deionized water in a $600-\mathrm{mL}$ beaker. Second, the support material was added to this solution so as to attain an initial ratio of $2: 1$ for $\mathrm{ZnCl}_{2}$ to the catalyst support material. Third, the solution was stirred using a stir bar at $353 \mathrm{~K}$ for $3 \mathrm{~h}$ with the addition of deionized water from time to time into the solution if the water level decreased considerably. Finally, the $\mathrm{ZnCl}_{2}$-impregnated wet carbon foams were dried in an oven at $378 \mathrm{~K}$ for $48 \mathrm{~h}$. Then, the dried impregnated support material was placed in a stainless-steel tube for chemical activation, which was conducted at 873 $\mathrm{K}$ using a ramp rate of $5 \mathrm{~K} \mathrm{~min}^{-1}$ and a holding time of $2 \mathrm{~h}$ at the target temperature. Nitrogen gas was flushed through the reactor the entire time to avoid sample oxidation.

After wet impregnation and activation, the support material was refluxed with $3 \mathrm{M} \mathrm{HCl}$ for $1 \mathrm{~h}$ at 373 $\mathrm{K}$ to remove the remaining $\mathrm{ZnCl}_{2}$. The catalyst support material was filtered and washed with deionized water until the $\mathrm{pH}$ was neutral. Then, the support material was dried in an oven at $373 \mathrm{~K}$ for $24 \mathrm{~h}$. The dry material was then sieved, characterized, and further used to prepare the catalyst in the same way as that carried out for $\mathrm{S} 1$.

\subsection{Mineral acid treatment of $S 1$ and $S 2$ supports}

Surfaces of S1 and S2 materials were modified by treatment with $3 \mathrm{M} \mathrm{HNO}_{3}$ (A1) or $6 \mathrm{M} \mathrm{H}_{2} \mathrm{SO}_{4}$ (A2). Hereafter, these supports will be referred to as S1_A1, S1_A2 or S2_A1, S2_A2. The precise 
modification method was conducted as follows: In a 100-mL two-neck round-bottom flask, $50 \mathrm{~mL}$ of acid per $0.3 \mathrm{~g}$ of support was used. $\mathrm{HNO}_{3}$ treatment was conducted at $373 \mathrm{~K}$ for $2 \mathrm{~h}$, and $\mathrm{H}_{2} \mathrm{SO}_{4}$ treatment was conducted at $353 \mathrm{~K}$ for $3 \mathrm{~h}$. For S1 material, careful mixing was required to maintain an appropriate particle size of the material. After acid treatment, supports were washed with distilled water until the $\mathrm{pH}$ was neutral and subsequently placed in the oven at $373 \mathrm{~K}$.

\subsection{Catalyst preparation}

Prior to the dry impregnation of catalyst supports, pore volumes (PV) of all support materials were measured as described in the next section. The amount of metal salts, i.e., $\mathrm{Cu}\left(\mathrm{NO}_{3}\right)_{3} \cdot 2.5 \mathrm{H}_{2} \mathrm{O}$ and $\mathrm{Ni}\left(\mathrm{NO}_{3}\right)_{2} \cdot 6 \mathrm{H}_{2} \mathrm{O}$, inside the support were calculated so that the target concentration of metal was $5 \mathrm{w} \%$ each. Metal salts were dissolved in an exact amount of water to fill the PV of each support. Supports were mixed a few times with a spatula for $4-5 \mathrm{~h}$ and finally dried in an oven at $373 \mathrm{~K}$ for $24 \mathrm{~h}$. All catalysts were subjected to thermal treatment in a stainless-steel tube in a fixed-bed reactor under nitrogen. Thermal treatment was carried out at $773 \mathrm{~K}$ using a ramp rate of $5 \mathrm{~K} \mathrm{~min}^{-1}$ and a holding time of $2 \mathrm{~h}$ at the target temperature under a nitrogen flow $\left(10 \mathrm{~mL} \mathrm{~min}^{-1}\right)$.

\subsection{Characterization of catalyst materials}

The SSA and PSD were determined The SSA and PSD were determined for unreduced, thermally treated catalyst samples by nitrogen physisorption isotherms measured at $77.15 \mathrm{~K}$ on a Micromeritics ASAP 2020 instrument (Micromeritics Instruments, Norcross, GA, USA). Portions of each sample (100$200 \mathrm{mg}$ ) were degassed at a low pressure of $0.27 \mathrm{kPa}$ and at a temperature of $413 \mathrm{~K}$ for $2 \mathrm{~h}$ to remove adsorbed gas. Adsorption isotherms were obtained by the immersion of sample tubes in liquid nitrogen

$(77.15 \mathrm{~K})$ to achieve constant temperature conditions and by the addition of a small dose of gaseous nitrogen in samples. 
SSAs were calculated from adsorption isotherms according to the Brunauer-Emmett-Teller (BET) method [44]. Total PVs were calculated from adsorption isotherms at a $\mathrm{p} / \mathrm{p}_{0}$ ratio of 0.985 and in the case of the DFT [45] calculation as the total PV was measured at the maximum pore width. PSD was calculated by using the DFT algorithm under the assumption of slit-formed pores [46]. The distribution of PV (vol\%) was calculated from the individual volumes of micropores, mesopores, and macropores with the DFT model. t-Plot calculations were conducted using the Harkins and Jura method [47]. By using the instrumental setup, micropores down to a diameter of $1.5 \mathrm{~nm}$ can be measured even in case of possible contribution from smaller pores. The micropore areas and volumes were calculated by the t-plot algorithm. A previous study has reported that SSAs are typically measured with a precision of 5\% [48].

Compressive strengths $(\sigma)$ of S1 and S2 supports were determined before and after thermal treatment at $1073 \mathrm{~K}$ for $2 \mathrm{~h}$ using a Zwick/Roell Z010 testing machine (Kennesaw, Georgia, with a load cell of 10 $\mathrm{kN})$. The loading speed was $0.1 \mathrm{~mm} / \mathrm{s}$, and the measurement ended when the force decreased by $50 \%$ from the maximum or deformation reached $30 \%$. The compressive strength of pieces, with diameters of $1.1 \mathrm{~cm} \times 1.5 \mathrm{~cm} \times 0.4 \mathrm{~cm}$, was measured and calculated using Equation 1,

$\sigma=F / A$,

where $F(\mathrm{~N})$ is the maximum force at the linear region of the compression curve, and $A\left(\mathrm{~mm}^{2}\right)$ is the surface area. The accuracy of the instrument was $\pm 1 \%$.

Metal contents of the unreduced, thermally treated catalysts were measured by inductively coupled optical emission spectrometry (ICP-OES) using a Perkin Elmer Optima 5300 DV instrument. First, 0.1$0.2 \mathrm{~g}$ of samples were digested in a microwave oven (MARS, CEM Corporation) with $9 \mathrm{~mL}$ of $\mathrm{HNO}_{3}$ at $473 \mathrm{~K}$ for $10 \mathrm{~min}$. Second, $3 \mathrm{~mL}$ of $\mathrm{HCl}$ was added, and the mixture was digested at $473 \mathrm{~K}$ for $10 \mathrm{~min}$. Finally, $1 \mathrm{~mL}$ of $\mathrm{HF}$ was added, and the mixture was digested again at $473 \mathrm{~K}$ for $10 \mathrm{~min}$. Excess $\mathrm{HF}$ was 
neutralized using $\mathrm{H}_{3} \mathrm{BO}_{3}$ by heating at $443 \mathrm{~K}$ for $10 \mathrm{~min}$. Next, the solution was diluted to $50 \mathrm{~mL}$ with water, and the elements were analyzed by ICP-OES.

Prior to the mineral acid treatment, elemental analysis of support materials S1 and S2, i.e., carbon, hydrogen, nitrogen, sulfur, and oxygen, was conducted on a Perkin Elmer 2400 Series II CHNS/O device. These measurements were conducted in triplicate.

$\mathrm{X}$-ray diffraction $(\mathrm{XRD})$ patterns for the unreduced, thermally treated catalyst samples were recorded on a PANalytical X'Pert Pro X-ray diffraction system using monochromatic CuK $\alpha 1$ radiation $(\lambda=1.5406$ $\AA$ ) at $45 \mathrm{kV}$ and $40 \mathrm{~mA}$. Diffractograms were recorded in a $2 \theta$ range of $8-90^{\circ}$ at intervals of $0.017^{\circ}$ and with a scan step time of $80 \mathrm{~s}$. Crystalline phases and structures were analyzed by HighScore Plus software (Version 4.0, PANalytical BV, Almelo, The Netherlands). The peaks were identified using International Centre for Diffraction Data ( ICDD, PDF-4+ 2020).

X-ray photoelectron spectroscopy (XPS) profiles were recorded for the unreduced, thermally treated catalyst samples on a Thermo Fisher Scientific ESCALAB 250Xi XPS System. The catalyst samples were placed on an indium film with a pass energy of $20 \mathrm{eV}$ and a spot size of $900 \mu \mathrm{m}$, and the accuracy of the reported binding energies (BE) was $\pm 0.2 \mathrm{eV}$. $\mathrm{Ni}, \mathrm{Cu}$ as well as $\mathrm{O}, \mathrm{C}$, and $\mathrm{N}$ XPS profiles were measured for all samples. Measurement data were analyzed by Avantage V5. The monochromatic AlK $\alpha$ radiation $(1486.7 \mathrm{eV})$ was utilized from an $\mathrm{X}$-ray gun operated at $20 \mathrm{~mA}$ and $15 \mathrm{kV}$. Charge compensation was utilized to determine the obtained spectra, and the calibration of the BE was performed by utilizing the $\mathrm{C} 1 \mathrm{~s}$ line at $284.8 \mathrm{eV}$ as the reference.

The morphology of the unreduced, thermally treated catalyst particles was observed on a JEOL JEM2200FS energy-filtered transmission electron microscope equipped with a scan generator (EFTEM/SEM). Catalyst samples were dispersed in pure ethanol and pretreated in an ultrasonic bath for several minutes to create a microemulsion. A small drop of the microemulsion was deposited on a copper grid precoated with carbon (Lacey/Carbon 200 Mesh Copper) and evaporated in air at room temperature. For the 
measurement, an accelerating voltage of $200 \mathrm{kV}$ was utilized, and the resolution of the scanning TEM (STEM) image was $0.2 \mathrm{~nm}$. Particle sizes of metal and metal oxides (both $\mathrm{Cu}$ and $\mathrm{Ni}$ ) were calculated from TEM images using a PDF-Xchange Editor program.

\subsection{Furfural hydrotreatment experiments}

Furfural hydrotreatment experiments were conducted in a 50-mL batch reactor (Parker Autoclave Engineers). In the experiments, $0.2 \mathrm{~g}$ (with an accuracy of four decimals) of the catalyst was reduced in situ (523 K, $2 \mathrm{~h}, 40$ bar $\mathrm{H}_{2}$ ), followed by the mixing of $1 \mathrm{~mL}$ of furfural and $15 \mathrm{~mL}$ of solvent (i.e., 2propanol) and their subsequent addition into the reactor from a pressurized feed tank under a $\mathrm{H}_{2}$ pressure of 40 bar at the desired reaction temperature of $503 \mathrm{~K}$. The reactor was heated to the desired reaction temperature before adding the feed. A stirring speed of $800 \mathrm{rpm}$ was used for all experiments, and the catalyst formed a slurry with the reaction mixture. After the reaction, the reactor was cooled to room temperature with an ice bath, and a sample was taken from the gas phase into an evacuated container. Another sample was taken from the liquid phase for analysis. Reactions times of 30, 120, and $300 \mathrm{~min}$ were applied.

Product analysis was performed by a similar method as that reported in our previous study [49]. Gas samples were analyzed on an Agilent 6890 Series gas chromatography (GC) system with a flame ionization detector (FID) and a thermal conductivity detector (TDC). $\mathrm{CO}, \mathrm{CO}_{2}, \mathrm{H}_{2}$, and $\mathrm{N}_{2}$ were analyzed by TCD, which was connected to two columns: HP-PLOT/Q $(30 \mathrm{~m} \times 0.53 \mathrm{~mm} \times 40 \mu \mathrm{m})$ and HP Molesieve $(30 \mathrm{~m} \times 0.53 \mathrm{~mm} \times 25 \mu \mathrm{m})$ columns. Hydrocarbons were analyzed by FID, which was connected to an HP-AL/KCL column $(50 \mathrm{~m} \times 0.32 \mathrm{~m} \times 8 \mu \mathrm{m})$. The heating program started from $313 \mathrm{~K}$ (holding time of $9.5 \mathrm{~min}$ ) at a heating rate of $10 \mathrm{~K} \mathrm{~min}^{-1}$ up to $473 \mathrm{~K}$. The inlet temperature was $473 \mathrm{~K}$. The liquid samples were analyzed on an Agilent 6890 Series GC system, equipped with an FID and a Zebron ZB-wax Plus column $(60 \mathrm{~m} \times 0.25 \mathrm{~mm} \times 0.25 \mu \mathrm{m})$. The inlet temperature was $503 \mathrm{~K}$, and the heating program started at $313 \mathrm{~K}$ at a heating rate of $5 \mathrm{~K} \mathrm{~min}^{-1}$ until $373 \mathrm{~K}$ and at a heating rate of $20 \mathrm{~K}$ 
$\min ^{-1}$ until $503 \mathrm{~K}$. The injection volume was $1 \mu \mathrm{L}$, and the internal standard was 2-butanol. Most of the compounds were calibrated. For those compounds that could not be calibrated, FID response factors were estimated according to the study reported by Scanlon and Willis [50] and the corrections provided by Jorgensen et al. [51]. For compound identification, Agilent GC-MS (7890-5975) was employed using a similar column and temperature program as described earlier. Mass spectra were recorded at an electron impact ionization of $70 \mathrm{eV}$.

Conversion, selectivity, and batch residence times were calculated as follows. Furfural conversion $(X)$ was calculated using Equation 2,

$X=\left(C_{\mathrm{F} 0}-C_{\mathrm{Ft}}\right) / C_{\mathrm{F} 0}$,

where $C_{\mathrm{F} 0}$ is the concentration of furfural (mmol g ${ }^{-1}$ sample) in the feed, and $C_{\mathrm{Ft}}$ is the concentration of furfural (mmol g $\mathrm{g}^{-1}$ sample) at the reaction time $t$. Product selectivity $(S)$ and yield $(Y)$ were calculated using Equation 3 and 4, respectively,

$S_{\mathrm{i}}=C_{\mathrm{it}} /\left(C_{\mathrm{F} 0}-C_{\mathrm{Ft}}\right)$,

$Y_{\mathrm{i}}=C_{\mathrm{it}} / C_{\mathrm{F} 0}$

where $C_{\mathrm{it}}$ is the concentration of the product $i\left(\mathrm{mmol} \mathrm{g}^{-1}\right.$ sample) at the reaction time $t$. Batch residence time $(\tau)$ [ $\mathrm{g}_{\text {cat }}$ min $\left.\mathrm{g}_{\text {reactant }}{ }^{-1}\right]$ was calculated according to references [52,53] and used instead of reaction time to increase accuracy.

$\tau=\left(\mathrm{m}_{\text {cat }} t\right) / \mathrm{m}_{\text {reactant }}$

where $\mathrm{m}_{\text {cat }}$ is the mass of the catalyst, and $\mathrm{m}_{\text {reactant }}$ the mass of furfural added to the reactor.

\section{Results and Discussion}

3.1. Characterization of the AC foams and catalysts 
Table 1 provides the detailed description of sample names. Two ACF were prepared, i.e., physical activation with steam, which was microporous (denoted $\mathrm{S} 1$ ), and chemical activation with $\mathrm{ZnCl}_{2}$, which was mainly mesoporous (denoted S2), respectively. Surface properties of the foams were tailored by acid washing with $\mathrm{HNO}_{3}\left(\mathrm{~S} 1 \_\mathrm{A} 1\right.$ and $\left.\mathrm{S} 2 \_\mathrm{A} 1\right)$ and $\mathrm{H}_{2} \mathrm{SO}_{4}\left(\mathrm{~S} 1 \_\mathrm{A} 2\right.$ and $\left.\mathrm{S} 2 \_\mathrm{A} 2\right)$. In addition, as references, two commercial AC supports were used, i.e., steam-activated (Norit_S) and acid-washed (Norit_A) supports, respectively. In addition, a biobased AC support from spruce (S3, for reference) was prepared by the steam activation of sawdust.

Table 1

Detailed description of supports and catalyst used in this study.

\begin{tabular}{lll}
\hline Sample name & Type & Description \\
\hline S1 & Support & Support 1, prepared from tannic acid and activated with steam. \\
S1_A1 & Support & S1, treated with $\mathrm{HNO}_{3}$. \\
S1_A2 & Support & S1, treated with $\mathrm{H}_{2} \mathrm{SO}_{4}$. \\
S1_Cu/Ni & Catalyst & S1, impregnated with $\mathrm{Cu}$ and Ni, thermally treated, ready catalyst. \\
S1_A1_Cu/Ni & Catalyst & S1_A1, impregnated with Cu and Ni, thermally treated, ready catalyst. \\
S1_A2_Cu/Ni & Catalyst & S1_A2, impregnated with Cu and Ni, thermally treated, ready catalyst. \\
S2 & Support & Support 2, prepared from pine bark extracts and activated with ZnCl. \\
S2_A1 & Support & S2, treated with $\mathrm{HNO}_{3}$. \\
S2_A2 & Support & S2, treated with $\mathrm{H}_{2} \mathrm{SO}$. \\
S2_Cu/Ni & Catalyst & S2, impregnated with Cu and Ni, thermally treated, ready catalyst. \\
S2_A1_Cu/Ni & Catalyst & S2_A1, impregnated with Cu and Ni, thermally treated, ready catalyst. \\
S2_A2_Cu/Ni & Catalyst & S2_A2, impregnated with Cu and Ni, thermally treated, ready catalyst. \\
S3 & Support & Steam-activated carbon prepared from spruce sawdust. \\
S3_Cu/Ni & Catalyst & S3, impregnated with Cu and Ni, thermally treated, ready catalyst. \\
Norit_S & Support & Commercial steam-activated carbon support material. \\
Norit_S_Cu/Ni & Catalyst & Norit_S, impregnated with Cu and Ni, thermally treated, ready catalyst. \\
Norit_A & Support & Commercial steam-activated carbon support treated with acid. \\
Norit_A_Cu/Ni & Catalyst & Norit_A, impregnated with Cu and Ni, thermally treated, ready catalyst. \\
\hline
\end{tabular}

\subsection{Specific surface area and pore size distributions}

Table 2 summarizes the SSA and PSD results. The prepared S1 support exhibited a moderate SSA and PV. According to the DFT model, the S1 support mainly comprised micropores. t-Plot calculation, which used the Harkins and Jura method [47], and the adsorption isotherm (Fig. S1 in Supplementary Material) confirmed that the pores created in the S1 support are almost completely micropores. By the treatment of the S1 support with acids, SSA and PV decreased, most probably due to the collapse of pores 
[54]. According to the results shown in Table 2, compared to the S1 support, the S2 support exhibited a higher SSA and PV, with a 55 vol\% mesoporous structure. Similarly, acid treatment $\left(\mathrm{HNO}_{3}\right)$ led to the decrease in the SSA and PV of S2. However, sulfuric acid treatment did not affect the SSA or PV of S2; the reason for this result is not clear thus far. The SSA and PV of Norit_A were similar to those of the S2 support. A major difference between these two supports was the PSD. A similar difference was observed between S3 and Norit_S supports: After impregnation and thermal treatment, the SSA and PV mainly decreased. 
Table 2

Specific surface area (SSA), pore volume (PV), pore size distribution (PSD), and average pore size of the prepared supports and catalysts analyzed by $\mathrm{N}_{2}$ adsorption isotherms.

\begin{tabular}{|c|c|c|c|c|c|c|c|c|c|c|c|c|c|c|c|c|c|}
\hline \multirow[b]{2}{*}{ Calculation method } & \multirow[b]{2}{*}{ Unit } & \multicolumn{12}{|c|}{ Prepared supports/catalysts } & \multicolumn{4}{|c|}{ Commercial supports/catalysts } \\
\hline & & $\begin{array}{c}\text { Support } \\
\text { S1 }\end{array}$ & $\begin{array}{l}\text { Support } \\
\text { S1_A1 }\end{array}$ & $\begin{array}{l}\text { Support } \\
\text { S1_A2 }\end{array}$ & $\begin{array}{c}\text { Catalyst } \\
\text { S1_A1 } \\
\mathrm{Cu} / \mathrm{Ni}\end{array}$ & $\begin{array}{c}\text { Catalyst } \\
\text { S1_A2 } \\
\mathrm{Cu} / \mathrm{Ni}\end{array}$ & $\begin{array}{c}\text { Support } \\
\text { S2 }\end{array}$ & $\begin{array}{l}\text { Support } \\
\text { S2_A1 }\end{array}$ & $\begin{array}{l}\text { Support } \\
\text { S2_A2 }\end{array}$ & $\begin{array}{c}\text { Catalyst } \\
\text { S2_A1 } \\
\text { Cu/Ni }\end{array}$ & $\begin{array}{c}\text { Catalyst } \\
\text { S2_A2 } \\
\mathrm{Cu} / \mathrm{Ni}\end{array}$ & $\begin{array}{c}\text { Support } \\
\text { S3 }\end{array}$ & $\begin{array}{c}\text { Catalyst } \\
\text { S3 } \\
\mathrm{Cu} / \mathrm{Ni}\end{array}$ & $\begin{array}{l}\text { Support } \\
\text { Norit_A }\end{array}$ & $\begin{array}{c}\text { Catalyst } \\
\text { Norit_A } \\
\mathrm{Cu} / \mathrm{Ni}\end{array}$ & $\begin{array}{l}\text { Support } \\
\text { Norit_S }\end{array}$ & $\begin{array}{c}\text { Catalyst } \\
\text { Norit_S } \\
\mathrm{Cu} / \mathrm{Ni}\end{array}$ \\
\hline \multicolumn{18}{|l|}{ BET } \\
\hline SSA & $\mathrm{m}^{2} \mathrm{~g}^{-1}$ & 560 & 332 & 381 & 549 & 469 & 1361 & 911 & 1395 & 715 & 1151 & 891 & 683 & 1381 & 1152 & 961 & 756 \\
\hline Pore volume & $\mathrm{cm}^{3} \mathrm{~g}^{-1}$ & 0.24 & 0.14 & 0.16 & 0.24 & 0.21 & 0.89 & 0.53 & 0.91 & 0.38 & 0.71 & 0.60 & 0.46 & 0.63 & 0.53 & 0.43 & 0.34 \\
\hline \multicolumn{18}{|l|}{ t-Plot } \\
\hline Micropore volume & $\mathrm{cm}^{3} \mathrm{~g}^{-1}$ & 0.19 & 0.11 & 0.13 & 0.19 & 0.16 & 0.07 & 0.13 & 0.07 & 0.14 & 0.10 & 0.20 & 0.15 & 0.41 & 0.34 & 0.32 & 0.25 \\
\hline Micropore area & $\mathrm{m}^{2} \mathrm{~g}^{-1}$ & 482 & 280 & 324 & 469 & 405 & 148 & 297 & 148 & 348 & 228 & 486 & 362 & 1023 & 859 & 810 & 630 \\
\hline External surface area & $\mathrm{m}^{2} \mathrm{~g}^{-1}$ & 79 & 52 & 56 & 80 & 64 & 1213 & 613 & 1247 & 367 & 924 & 405 & 321 & 358 & 293 & 151 & 126 \\
\hline \multicolumn{18}{|l|}{ DFT } \\
\hline Average pore size & $\mathrm{Nm}$ & $<1.5$ & $<1.5$ & $<1.5$ & $<1.5$ & $<1.5$ & 2.2 & 1.8 & 2.2 & 1.9 & 2.1 & 2.0 & 2.0 & 1.6 & 1.5 & 1.5 & 1.5 \\
\hline Pore volume & $\mathrm{cm}^{3} \mathrm{~g}^{-1}$ & 0.20 & 0.12 & 0.13 & 0.19 & 0.17 & 0.76 & 0.44 & 0.78 & 0.31 & 0.61 & 0.51 & 0.39 & 0.51 & 0.42 & 0.34 & 0.27 \\
\hline Micropores & $\%$ & 96 & 93 & 96 & 95 & 95 & 45 & 57 & 45 & 69 & 50 & 50 & 49 & 89 & 90 & 94 & 93 \\
\hline Mesopores & $\%$ & 4 & 4 & 4 & 5 & 5 & 55 & 43 & 55 & 31 & 50 & 50 & 51 & 11 & 10 & 6 & 7 \\
\hline Macropores & $\%$ & 0 & 3 & 0 & 0 & 0 & 0 & 0 & 0 & 0 & 0 & 0 & 0 & 0 & 0 & 0 & 0 \\
\hline
\end{tabular}




\subsection{Compressive strength and elemental analysis of $S 1$ and $S 2$ supports}

Table 3 summarizes the results obtained from compressive strength measurements. A clear difference in compressive strengths between uncarbonized (no thermal treatment) and carbonized (high-temperature thermal treatment) S1 and S2 supports was observed, which was in good agreement with previously published results [39]. The compressive strength of the support before and after carbonization was compared to confirm that a more stable structure is obtained by thermal treatment. The matured support S1 exhibited a compressive strength of $0.040 \mathrm{MPa}$, and after thermal treatment, its compressive strength was nearly three times higher $(0.142 \mathrm{MPa})$. The same observation was made for the S2 support: After thermal treatment, the mechanical strength was two times higher. Notably, the comparison of the compressive strengths between S1 and S2 supports revealed significant differences. Uncarbonized S2 was almost 30 times stronger than uncarbonized S1. In addition, the thermally treated S2 support was more than 15 times stronger than the S1 support.

Such a large difference in the compressive strength between S1 and S2 was related to the different compositions of the raw materials. The S1 support was prepared using tannic acid, while support S2 was prepared using pine bark extracts extracted with a 30/70 w\% water/ethanol solution. Although the exact composition of the extracts was not known, but the extracts undoubtedly contained sugars, lignin, and different tannins. Carbon foams prepared using tannic acid are known to be rather fragile (Table 3). According to results obtained herein, the mechanical stability of tannic-acid-based carbon foams can be enhanced by using a complex mixture of phenolic substances. An increased number of crosslinking molecules, such as lignin and sugars, are present in the foam solution, which in turn increase the rigidity of foam structure during polymerization.

Table 3

Compressive strengths of matured precursor and thermally treated support materials (S1 and S2).

\begin{tabular}{ccccc}
\hline \multirow{2}{*}{ Support } & \multicolumn{2}{c}{ Matured } & \multicolumn{2}{c}{ Thermally treated } \\
\cline { 2 - 5 } & Precursor to S1 & Precursor to S2 & Support S1 & Support S2 \\
\hline $\begin{array}{c}\text { Average compressive } \\
\text { strength }(\mathrm{MPa})\end{array}$ & 0.040 & 1.15 & 0.142 & 2.29 \\
\hline
\end{tabular}


Table 4 below summarizes the elemental analysis of the thermally treated supports S1 and S2. As expected, both supports exhibited a high carbon content of greater than $80 \mathrm{w} \%$. Sulfur and nitrogen contents of the supports were similar, but higher contents of hydrogen (33\%) and oxygen (15\%) were observed in support $\mathrm{S} 1$, related to the different compositions of the raw material.

Table 4

Elemental analysis for carbon, hydrogen, nitrogen, sulfur, and oxygen determined on the Perkin Elmer 2400 Series II CHNS/O device.

\begin{tabular}{cccccc}
\hline \multirow{2}{*}{ Sample } & \multicolumn{3}{c}{ Determined values } \\
\cline { 2 - 6 } & $\mathbf{C}(\mathbf{w} \%)$ & $\mathbf{H}(\mathbf{w} \%)$ & $\mathbf{N}(\mathbf{w} \%)$ & $\mathbf{S}(\mathbf{w} \%)$ & $\mathbf{O}(\mathbf{w} \%)$ \\
\hline Support S1 & $80 \pm 5$ & $14 \pm 2$ & $1.1 \pm 0.4$ & $<0.1$ & $4.6 \pm 0.6$ \\
Support S2 & $86 \pm 4$ & $9.4 \pm 0.5$ & $0.7 \pm 0.1$ & $<0.1$ & $3.9 \pm 0.1$ \\
\hline
\end{tabular}

\subsection{Metal content}

Metal contents of the catalysts were estimated by ICP-OES. Table 5 summarizes the results. The target metal contents of $\mathrm{Ni}$ and $\mathrm{Cu}$ in the supported catalysts were $5 \mathrm{w} \%$. The measured metal contents of the impregnated and thermally treated S1_A2_Cu/Ni, S2,_A2_Cu/Ni, S3_Cu/Ni, Norit_S_Cu/Ni, and Norit_A_Cu/Ni catalysts were close to the target values. However, the contents of nickel and copper in S1_A1_Cu/Ni and S2_A1_Cu/Ni were higher than expected. This result was possibly related to the acid treatment with $\mathrm{HNO}_{3}$, which increased the oxygen content of the supports (Table S1 in the Supplementary Material). The surface oxygen might have burned away some carbon from the surface during thermal treatment; hence, the weight percentage of the metal in the catalysts increases. Moreover, the content of impurities such as $\mathrm{Zn}$ and $\mathrm{S}$, which remained after the pretreatment of the catalysts, was measured. The limits of detection for $\mathrm{Zn}$ metal and sulfur were 0.4 $\mathrm{mg} / \mathrm{kg}$ and $<20000 \mathrm{mg} / \mathrm{kg}$, respectively. Zn impurity levels were relatively low, most probably related to the reactor used for the activation of supports or thermal treatment of the catalysts. Most of the 
catalysts exhibited $\mathrm{S}$ content of less than 2 w\%. Only S2_A2_Cu/Ni exhibited a slightly higher S content due to the sulfuric acid treatment. In addition, compared to S1_A2_Cu/Ni, S2_A2_Cu/Ni exhibited a higher PV (Table 2), indicating that the adsorption of sulfur-containing groups inside the pores of S2_A2_Cu/Ni is better than that of $\mathrm{S} 1 \_\mathrm{A} 2 \_\mathrm{Cu} / \mathrm{Ni}$.

Table 4

Elemental contents of the samples determined by ICP-OES.

\begin{tabular}{|c|c|c|c|c|c|}
\hline \multirow{2}{*}{ Sample } & \multirow{2}{*}{$\begin{array}{c}\text { Target values of } \\
\mathrm{Cu} \text { and } \mathrm{Ni} \\
(\mathrm{w} \%)\end{array}$} & \multicolumn{4}{|c|}{ Determined values } \\
\hline & & $\mathrm{Cu}(\mathrm{w} \%)$ & $\mathrm{Ni}(\mathrm{w} \%)$ & $\mathrm{Zn}(\mathrm{w} \%)$ & $\mathrm{S}(\mathrm{w} \%)$ \\
\hline S1_A1_Cu/Ni & 5.0 & 7.0 & 7.2 & 0.0060 & $<2$ \\
\hline $\mathrm{S} 1 \_\mathrm{A} 2 \_\mathrm{Cu} / \mathrm{Ni}$ & 5.0 & 5.0 & 5.1 & 0.014 & $<2$ \\
\hline S2_A1_Cu/Ni & 5.0 & 6.6 & 6.5 & 0.0030 & $<2$ \\
\hline S2_A2_Cu/Ni & 5.0 & 5.7 & 5.6 & 0.013 & 2.2 \\
\hline $\mathrm{S} 3 \_\mathrm{Cu} / \mathrm{Ni}$ & 5.0 & 4.3 & 4.3 & 0.0040 & $<2$ \\
\hline Norit_S_Cu/Ni & 5.0 & 3.8 & 4.0 & 0.019 & $<2$ \\
\hline Norit_A_Cu/Ni & 5.0 & 4.3 & 4.7 & 0.0020 & $<2$ \\
\hline
\end{tabular}

\subsection{X-ray photoelectron spectroscopy and X-ray diffraction analysis}

XPS (detection depth $<10 \mathrm{~nm}$ ) was employed to characterize the surface functionalities of the AC supports. XPS data, i.e., $\mathrm{C} 1 \mathrm{~s}, \mathrm{O} 1 \mathrm{~s}$, and $\mathrm{N}_{2 \mathrm{p}}$ profiles, of untreated and acid-treated supports were analyzed. Table S1 and S2 in Supplementary Material summarize the XPS results of the supports and catalysts, respectively. From the $\mathrm{C} 1$ s spectra, carbon-containing groups were deconvoluted into five peaks based on (BE) (Table S1 and S2 and Fig. S4(a) in Supplementary Material), i.e., carbon-carbon bonds $(\mathrm{BE}=284.8 \mathrm{eV})$, carbon species in alcohol or ether groups $(\mathrm{BE}=286.3-287.0 \mathrm{eV})$, carbon in carbonyl groups $(\mathrm{BE}=287.5-288.1 \mathrm{eV})$, carbon in carboxyl or ester groups $(\mathrm{BE}=289.3-290.0 \mathrm{eV})$, and shake-up satellites due to $\pi-\pi *$ transition in aromatic rings $(\mathrm{BE}=291.2-292.1 \mathrm{eV})$, respectively [55]. According to C1s scans, the support S1 and S2 surfaces predominantly comprised carbon- 
carbon-type bonds, with some oxygen-containing functional groups. In addition, low levels of aromatic rings (from $\pi-\pi^{*}$ transitions) were detected. In addition, the total oxygen content from O1s data was calculated (Tables S1 and S2 in Supplementary Material), which revealed some oxygen functionalities ( $\leq 10 \%$ from surface functionalities) on the S1 and S2 supports. Moreover, the surfaceoxygen functionalities on S2 were slightly less (4\%) than those on S1 (10\%). Commercial and S3 supports exhibited a similar surface composition $(\mathrm{C} 1 \mathrm{~s}, \mathrm{O} 1 \mathrm{~s})$, especially $\mathrm{S} 1$. The highest amount of oxides was observed on support S1_A1 (Table S1 and Fig. S4(b)), which was four times greater than that observed for the untreated $\mathrm{S} 1$ support. In addition, $\mathrm{H}_{2} \mathrm{SO}_{4}$ treatment led to the increase in the oxygen content on support S1, and it was two times greater than the oxygen content for the untreated $\mathrm{S} 1$ support. For $\mathrm{S} 2$, the same effect was observed, and $\mathrm{HNO}_{3}$ treatment led to the increase in the oxygen functionalities on the support in comparison with that observed for $\mathrm{H}_{2} \mathrm{SO}_{4}$ treatment. Overall, compared to support S2, support S1 exhibited a higher amount of oxides as detected by XPS. Supports exhibited a small amount of nitrogen as observed by XPS $\mathrm{N} 2{ }_{\mathrm{p}}$ scans $(<0.5 \%)$; however, $\mathrm{HNO}_{3}$ treatment possibly led to the increase in the nitrogen content due to the addition of nitrates on the surface, which were observed at $405 \mathrm{eV}$ in the $\mathrm{N} 1_{2 \mathrm{p}} \mathrm{XPS}$ spectrum.

XPS verified the successful addition of metals in the case of impregnated (thermal treatment and unreduced) catalysts. XPS data for the $\mathrm{Cu}_{2 p}$ and $\mathrm{Ni}_{2 p}$ spectra revealed the presence of metal oxides (such as $\mathrm{CuO}$ and $\mathrm{NiO}$ ) in thermally treated, unreduced catalysts (Table $\mathrm{S} 2$ ). The $\mathrm{Cu}_{2 \mathrm{p}}$ scans revealed peaks at $\sim 932$ and $\sim 933 \mathrm{eV}$ for all catalysts, which were attributed to $\mathrm{Cu}$ metal and metal oxides of $\mathrm{Cu}_{2} \mathrm{O}$ and $\mathrm{CuO}$, respectively [56]. Owing to similar $\mathrm{BE}$ of $\mathrm{Cu}(932.6 \mathrm{eV})$ and $\mathrm{Cu}_{2} \mathrm{O}(932.7 \mathrm{eV}), \mathrm{XRD}$ measurements were also carried out to identify the phases. For the $\mathrm{S} 1\left(\mathrm{HNO}_{3}\right.$ and $\left.\mathrm{H}_{2} \mathrm{SO}_{4}\right)$-supported catalyst, satellites at $\sim 943 \mathrm{eV}$ were detected, indicative of the presence of $\mathrm{Cu}$ (II) (Fig. S5(a) S1_A2_Cu/Ni). This result was in agreement with XRD results (Fig. S3): $\mathrm{CuO}$ was present (at $2 \theta=$ $35.5^{\circ}$ and $38.7^{\circ}$ ), and a metal copper phase was absent. For S2-supported catalysts, satellite peaks at 
$943 \mathrm{eV}$ were not detected, indicative of the presence of $\mathrm{Cu}(\mathrm{I})$ or the $\mathrm{Cu}$ metal (Fig S5(b) S2_A2_Cu/Ni); this result was also in agreement with the $\mathrm{XRD}$ results: $\mathrm{CuO}$ and $\mathrm{Cu}_{2} \mathrm{O}$ peaks were not observed. From $\mathrm{Ni}_{2 \mathrm{p}}$ scans (Fig. S6), the main peak at $\sim 854 \mathrm{eV}$ and the broad satellite at $860 \mathrm{eV}$ revealed the presence of nickel oxide $\mathrm{NiO}$ and/or $\mathrm{Ni}$ in all catalysts [57]. In addition, for $\mathrm{S} 3$ and commercial AC-supported catalysts, the presence of copper and nickel oxides was verified.

Compared with that of $\mathrm{S} 1 \_\mathrm{A} 2$, the $\mathrm{O} 1 \mathrm{~s}$ scan of $\mathrm{S} 1 \_\mathrm{A} 2 \_\mathrm{Cu} / \mathrm{Ni}$ revealed an increased peak intensity at a BE range of 529-530 eV, indicative of the presence of $\mathrm{M}-\mathrm{O}$ bonds. Compared with the O1s $(\mathrm{BE}=531.2 \mathrm{eV})$ of S1_A2 $(5.6$ atom\%, Table S1), the O1s $(\mathrm{BE}=531.2 \mathrm{eV})$ of S1_A2_Cu/Ni was 11.7 atom\% (Table S2), indicative of the increase in the number of $\mathrm{M}-\mathrm{O}$ bonds by the impregnenation of $\mathrm{Cu}$ and $\mathrm{Ni}$. XRD analysis was conducted for seven catalyst samples. Fig S3 in Supplementary Material shows the results. Cu (ICDD 04-002-8854) and Ni (ICDD 04-004-2759) metals were partly oxidized in all catalysts, except in the case of S1_A2_Cu/Ni, where total oxidation was observed. $\mathrm{CuO}$ (ICDD 00-048-1548), Cu2O (ICDD 04-016-6875), and NiO (ICDD 04-0233539) were formed. Additional peaks were observed at $41.7^{\circ}, 48.6^{\circ}$, and $71.2^{\circ}$ for $\mathrm{S} 1 \_\mathrm{A} 1 \_\mathrm{Cu} / \mathrm{Ni}$, which were not identified.

\subsection{Electron microscopy measurements}

The morphology of the thermally treated, unreduced catalyst particles was investigated by EFTEM in the STEM mode and by scanning electron microscopy (SEM). On the surface of supports, which were treated with acids A1 and A2, metals appeared to be quite evenly distributed (Fig. S2 in Supplementary Material). In all catalysts, especially nickel catalysts, homogeneously distributed particles $(10-40 \mathrm{~nm})$ were observed with a smaller particle size variation over the support than that observed for copper, where larger aggregates $(25-250 \mathrm{~nm})$ were observed, and the variation in the particle size was broader. On the S1 support, metal particle sizes for S1_A1_Cu/Ni were 60-70 nm 
and 10-20 nm for copper and nickel, respectively, and for S1_A2_Cu/Ni, particle sizes were 100$200 \mathrm{~nm}$ and 20-40 nm for copper and nickel, respectively. Particle sizes for S2_A1_Cu/Ni (Fig. 2c) were $25-50 \mathrm{~nm}$ and 7-10 $\mathrm{nm}$ for copper and nickel, respectively. On S2_A2_Cu/Ni (Fig. 2d), the variation in particle sizes for copper and nickel was 50-125 nm and 10-20 nm, respectively. Overall, the particles seemed to be smaller on support S2 than on support S1.

Variation in particle sizes between S1 and S2 supports can be partly explained by different PV and PSD (Table 1). The PV and pore size of S1 were less than those of the S2 support, possibly resulting in the agglomeration of metal particles on the catalyst surface as some micropore entrances can be blocked by large metal hydroxides [58]. In addition, notably, compared to $\mathrm{H}_{2} \mathrm{SO}_{4}$-treated supports, $\mathrm{HNO}_{3}$-treated $\mathrm{S} 1$ and $\mathrm{S} 2$ supports exhibited smaller metal particles, indicating that a higher surface oxygen content might be beneficial for the metal distribution; hence, the particle size is affected [59]. From the S3-supported catalyst, particle sizes for copper and nickel were 100-250 nm and $15-40 \mathrm{~nm}$, respectively. Particle sizes for copper in Norit_S_Cu/Ni and Norit_A_Cu/Ni were 15$45 \mathrm{~nm}$ and $25-80 \mathrm{~nm}$, respectively; the corresponding values for nickel were 7-15 nm and 15-25 $\mathrm{nm}$. Surface structures of the supports S1 and S2 were examined by SEM. The SEM images (Fig. S7 in the Supplementary Material) clearly revealed the presence of large ordered pores in both supports (S1 and S2). Fig. S8 in the Supplementary Material summarizes the size distribution, including Ni and $\mathrm{Cu}$ particles, which is calculated from the TEM images shown in Fig. 2. As an example, for S1_A1_Cu/Ni, $82.2 \%$ of the particle sizes were observed in the range of 8-28 nm, and $11.0 \%$ of the particles were observed in the range of $68-88 \mathrm{~nm}$. 

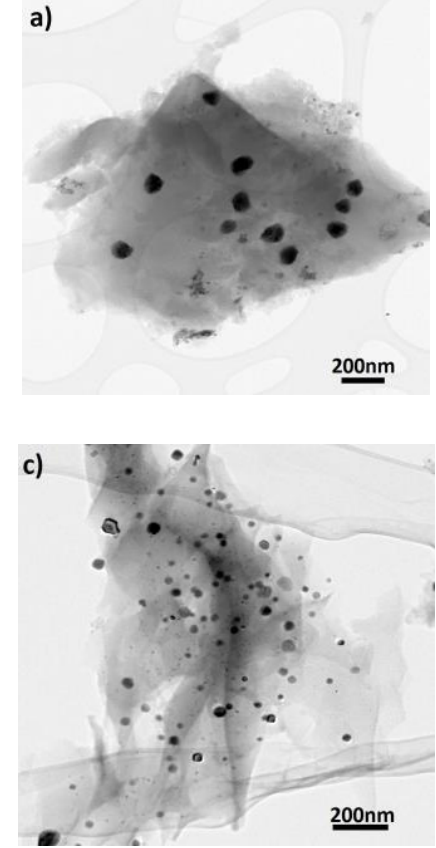

e)
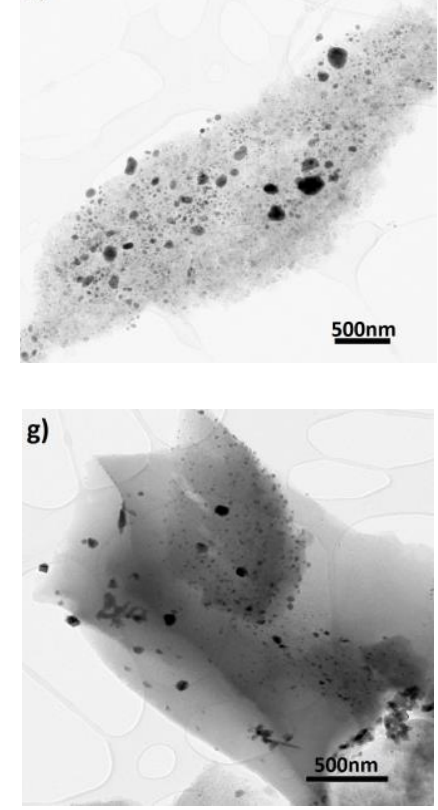
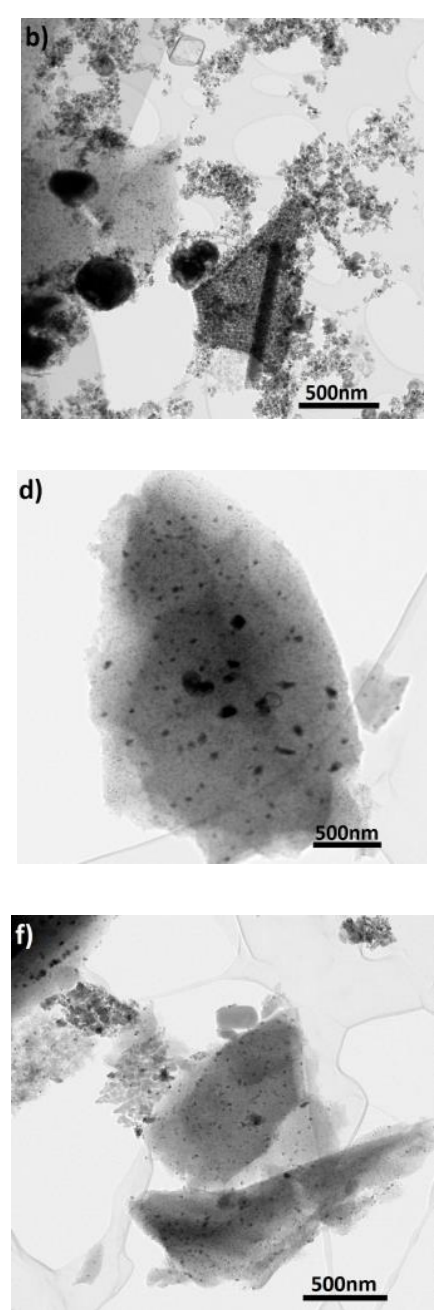


\subsection{Conversion of furfural to 2-methylfuran}

Scheme 1a and Scheme 1b show the furfural hydrotreatment and observed condensation products, respectively. The hydrotreatment of furfural to produce MF as the target product was investigated with the prepared $5-5 \% \mathrm{CuNi}$ catalysts on ACF (S1_Cu/Ni, S1_A1_Cu/Ni, S1_A2_Cu/Ni, S2_Cu/Ni, S2_A1_Cu/Ni, and S2_A2_Cu/Ni). In addition, 5-5\% CuNi catalysts were prepared on two commercial AC supports (i.e., Norit_S_Cu/Ni and Norit_A_Cu/Ni, respectively) and on biobased $\mathrm{AC}$ from spruce $\left(\mathrm{S} 3 \_\mathrm{Cu} / \mathrm{Ni}\right)$ and tested in the reaction just for comparison. The main interest is in the carbon foams. In addition to MF, FA, THFA, MTHF, and furan were obtained. Moreover, furfural ring-opening products, namely 5-hydroxy-2-pentanone (HPN), 1,4-pentanediol (PDOL), and 2-pentanone (PN), were observed. In addition, acetone was formed, which can be produced by 2-propanol via dehydrogenation or hydrogenation transfer, where 2-propanol acts as a hydrogen donor and concurrently forms acetone [60]. Two condensation products, i.e., furanmethanol acetate (FMA) and 2-(2-furylmethyl)-5-methylfuran (FMMF), were also obtained. 
a)
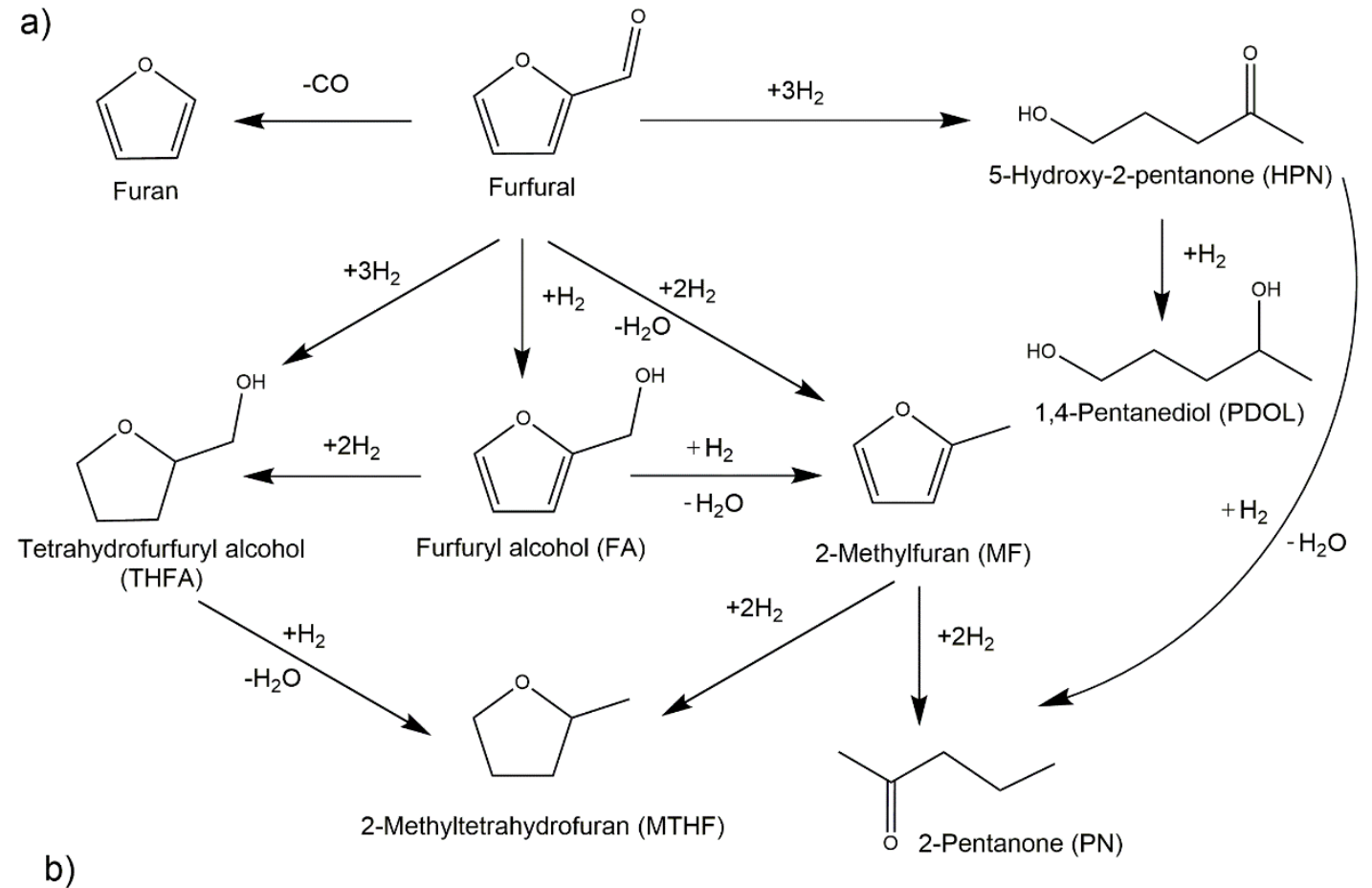

b)

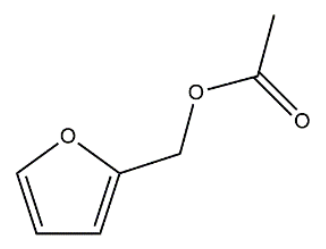

Furanmethanol acetate (FMA)

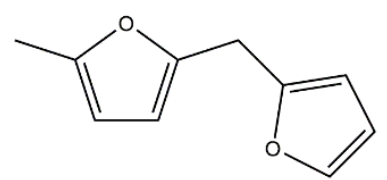

2-(2-Furanylmethyl)-5-methylfuran (FMMF)

Fig. 3a shows the conversion of furfural as a function of the batch residence time $(\tau$, defined as the catalyst mass divided by the reagent mass and multiplied with the reaction time) for the ACFsupported catalysts. Fig. 3b shows the conversion of furfural over the acid-washed ACF catalysts, and Fig. 3c shows the conversion over the reference catalysts. From the ACF supports, S1 was more active, leading to a furfural conversion of $100 \%$ after a reaction time of $300 \mathrm{~min}$. The higher activity of the $\mathrm{S} 1 \_\mathrm{Cu} / \mathrm{Ni}$ catalyst compared with that of the $\mathrm{S} 2 \_\mathrm{Cu} / \mathrm{Ni}$ catalyst was slightly surprising as the surface area of S1 was significantly lower (Table 2), and most of the pores in S1 were micropores, where the reaction can suffer from mass-transfer limitations; however, this was not observed for the reference catalysts. Overall, the selectivity of MF over ACF-based catalysts was not desirable. 
Acid washing exhibited an interesting effect on the catalytic activity (Fig. 3b). With $\mathrm{HNO}_{3}$ washing, the activity of the S1-supported catalyst decreased in the beginning of the reaction; this activity decrease was possibly related to the adverse effect of the acid treatment on the SSA and PV of the S1 catalyst; hence, the catalytic activity decreases. However, with support S2, a similar trend was not observed. For the support $\mathrm{S} 2, \mathrm{HNO}_{3}$ washing led to the increase in the catalytic activity throughout the range of the batch residence time. On the other hand, washing with $\mathrm{H}_{2} \mathrm{SO}_{4}$ led to the significant decrease in the activity of the $\mathrm{S} 1$ supported catalyst. Acid washing with $\mathrm{H}_{2} \mathrm{SO}_{4}$ can create anchoring sites for metal particles, leading to large agglomerates; the formation of these agglomerates could also decrease the activity. The loss in activity is also speculated to result from the sulphurcontaining groups from the support after the washing step. In case of the S2 support, washing with $\mathrm{H}_{2} \mathrm{SO}_{4}$ did not affect the catalytic activity. For both supports, compared to $\mathrm{H}_{2} \mathrm{SO}_{4}$ washing, washing with $\mathrm{HNO}_{3}$ led to a more active catalyst.

For comparison, the activities of $\mathrm{CuNi}$ on commercial supports and biobased $\mathrm{AC}$ were measured. Compared to most of the ACF-based catalysts, the reference catalysts exhibited higher activity (Fig. 3). Only CuNi supported on S1 (without acid washing) exhibited activity similar to those of the reference catalysts. Norit_A_Cu/Ni was the most active reference catalyst at low batch residence times, which is an acid-washed AC. At high batch residence times, a furfural conversion of almost $100 \%$ was achieved over all of the reference catalysts.

Fig. 4 shows the MF selectivity as a function of conversion. Compared to the S1_Cu/Ni catalyst, the S2_Cu/Ni catalyst exhibited higher MF selectivity even though the catalyst was less active (Fig. 3a). In general, the acid-washed catalysts were more selective toward MF. Among the acid-washed catalysts, $\mathrm{HNO}_{3}$-washed $\mathrm{S} 2$ exhibited the highest selectivity for $\mathrm{MF}$ as evidenced by a similar conversion of $\sim 90 \%$ (Fig. 3b). However, for the $\mathrm{H}_{2} \mathrm{SO}_{4}$-washed catalysts, a conversion of $\sim 60 \%$ (Fig. 3b) led to a similar MF selectivity. At a conversion of greater than $90 \%$, the S2_A1_Cu/Ni catalyst 
exhibited MF selectivity almost similar to those of the reference catalysts. In addition, the S2_A2_Cu/Ni catalyst exhibited an MF selectivity of $>40 \%$, but as the catalyst was less active, the conversion was less than $90 \%$.

a)

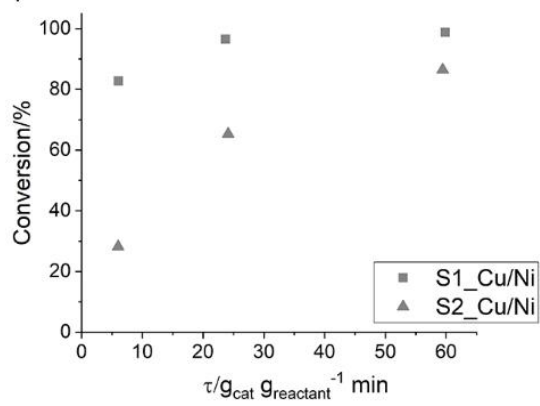

a)

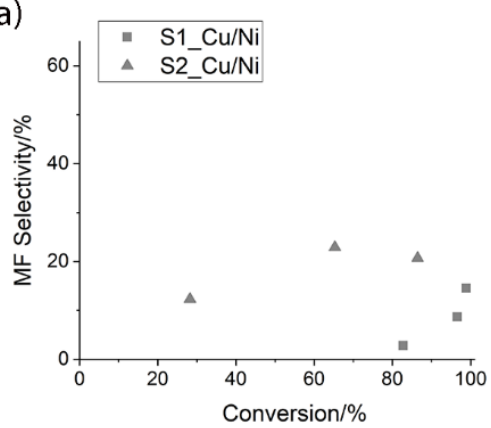

b)

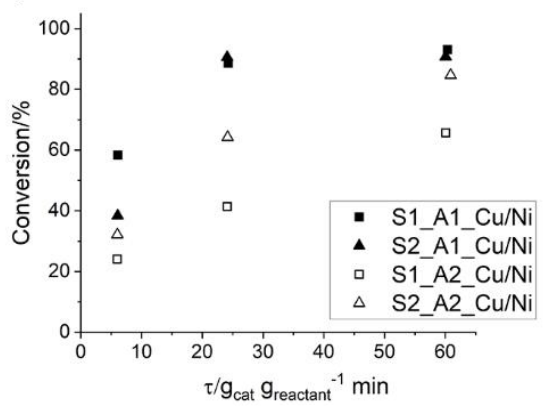

b)

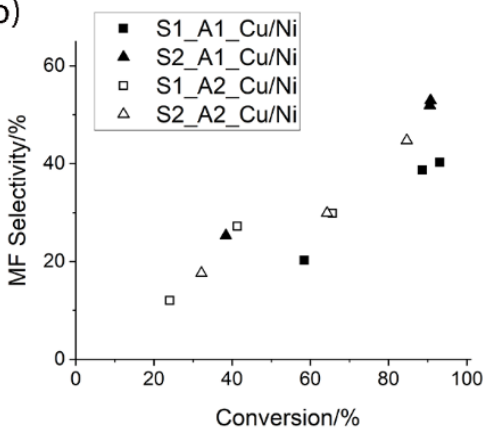

c)

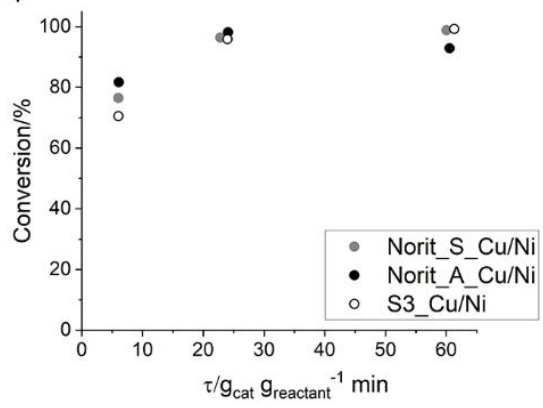

c)

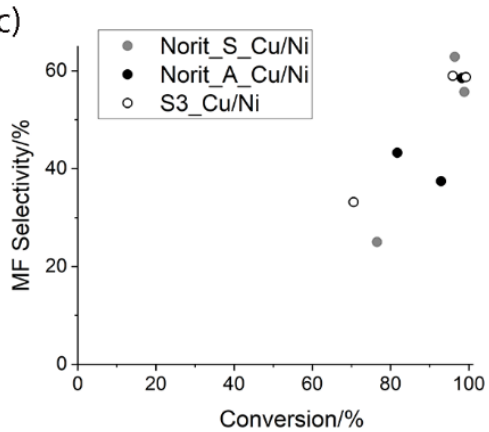

Table 5

Furfural conversion at the highest observed MF yield, the corresponding reaction time, and the main side-product yields.[a]

\begin{tabular}{llllllllll}
\hline Catalyst & $X$ & $t$ & $\tau$ & $\begin{array}{l}Y_{\mathrm{FA}} \\
{[\%]}\end{array}$ & $\begin{array}{l}Y_{\mathrm{MF}} \\
{[\mathrm{min}]}\end{array}$ & $\begin{array}{l}Y_{\text {THFA }} \\
{[\%]}\end{array}$ & $\begin{array}{l}Y_{\text {MTHF }} \\
{[\%]}\end{array}$ & $\begin{array}{l}Y_{\text {Furan }} \\
{[\%]}\end{array}$ & $\begin{array}{l}Y_{\text {FMA }} \\
{[\%]}\end{array}$ \\
\hline S1_Cuactant
\end{tabular}


[a] Reaction conditions: $503 \mathrm{~K}, 40$ bar $\mathrm{H}_{2}$, stirring at $800 \mathrm{rpm}, 0.2 \mathrm{~g}$ catalyst, $1 \mathrm{~mL}$ furfural, and $15 \mathrm{~mL}$ of 2-propanol.

Table 6 summarizes the product distribution at the highest observed MF yield for each catalyst. MF was the main product over the acid-washed ACF-based catalysts and the reference catalysts. As MF can further react to other products, the selectivity typically started to decrease after the maximum selectivity was reached. Only the catalysts on the commercial supports, i.e., Norit_S and Norit_A, exhibited the maximum MF yields during a 120-min reaction. The highest MF yield (61\%) was obtained for the Norit_S_Cu/Ni catalyst, the support of which is steam-activated commercial AC. The acid-washed commercial AC catalyst (Norit_A_Cu/Ni), steam-activated spruce-based AC (S3_Cu/Ni), and $\mathrm{HNO}_{3}$-washed ACF (S2_A1_Cu/Ni) also exhibited high MF yields of 57\%, 58\%, and $48 \%$, respectively. Compared to the ACF-supported catalysts, both acids (i.e., $\mathrm{HNO}_{3}$ and $\mathrm{H}_{2} \mathrm{SO}_{4}$ ) led to increased yield of the MF even though the conversions decreased in some cases. Better MF yields were probably related to the higher amount of surface oxygen groups in the catalysts (Supplementary Material Table S2), which are known to affect adsorption properties of ACs [31,61]. Although elemental and XPS analyses revealed a higher oxygen content for the support S1 compared to the support S2 even after acid washing, the MF yields over S1-based catalysts were lower. The considerably higher SSA and PV values for the mesoporous S2-based catalysts, as well as the microporous reference catalysts, seemed to be beneficial for the conversion of furfural to MF. Moreover, the furan yield over the S1-supported catalysts decreased after washing with acids, indicating that acid washing suppresses the undesired decarbonylation reaction. Without acid washing, ACF catalysts produced significant amounts of THFA or MTHF. All of the ACF-based catalysts (except S1_Cu/Ni) afforded FMA as a significant side product, whereas the reference catalysts afforded FMA only as a minor side product.

Previous studies have reported the highest MF yields of near $100 \%[13,31]$, which are obtained over $\mathrm{Cu}$ or Ir catalysts supported on charcoal-based ACs. However, ACs also can be prepared from 
renewable residual biomass materials [62]. Recently, the hydrotreatment of furfural over noble metals (such as Pt or Ru) and Ni supported on wood-based ACs [49] has been investigated. The highest MF yields (50\%) are obtained over noble-metal catalysts. To increase the mechanical strength [39] of the support material, biobased carbon foams were examined as a catalyst support for the hydrotreatment of furfural for the first time. The MF yield over the S2_A1_Cu/Ni catalyst was similar to that over the noble-metal catalysts on biobased AC reported previously [49]. However, a higher MF yield was obtained in this study with the biobased $\mathrm{AC}$ support $\left(\mathrm{S} 3 \_\mathrm{Cu} / \mathrm{Ni}\right)$. The visual observation of the liquid product recovered from the reactor after each experiment qualitatively revealed that the least and highest amounts of carbon dust are observed on the ACF catalysts and biobased AC (S3), respectively, indicative of the higher mechanical strength of carbon foams. Thus, further research is suggested to combine the activity of an AC-supported catalyst and the mechanical strength of ACFs.

In addition, non-noble metal catalysts for furfural hydrotreatment have been investigated. In our previous study, monometallic Ni catalysts are less active than noble metals, leading to the maximum MF yield of less than $40 \%$ [49]. However, the addition of $\mathrm{Cu}$ is known to significantly increase the catalytic activity of $\mathrm{Ni}[11,43]$. Gong et al. [31] have reported the beneficial combination of $\mathrm{CuO}_{\mathrm{x}}$ and $\mathrm{Cu}$ species on $\mathrm{AC}$ for $\mathrm{MF}$ production. They reported that the coexistence of $\mathrm{Cu}^{0}, \mathrm{Cu}^{+}$, and $\mathrm{Cu}^{2+}$ species can be controlled by the calcination temperature and time. In our XPS analysis, metallic $\mathrm{Cu}$ and $\mathrm{CuO}$ were found on most of the catalyst surfaces (Table S2 in the Supplementary Material); however; the XPS measurement was performed prior to catalyst reduction; thus, the presence of $\mathrm{CuO}$ after reduction is not known. Sitthisa and Resasco [63] have compared furfural hydrotreatment with silica-supported $\mathrm{Ni}$ and $\mathrm{Cu}$. With $\mathrm{Ni}$ catalysts, furan was the main product at all of the tested temperatures (483-523 K), but FA was the main product over $\mathrm{Cu}$. The Ni catalyst afforded ringopening products, which were not observed for the other catalysts [63]. In addition, Fu et al. [11] have compared the performance of monometallic $\mathrm{Cu}$ and $\mathrm{Ni}$ catalysts supported on $\mathrm{Al}_{2} \mathrm{O}_{3}$. They 
reported that the Ni catalyst is active for decarbonylation as well as for hydrogenation, resulting in a complex reaction network. The $\mathrm{Cu}$-based catalyst is less active, albeit highly selective for carbonyl hydrogenation, but the best selectivity for MF is achieved over $10 / 10 \mathrm{w} \% \mathrm{CuNi}$ on the $\mathrm{Al}_{2} \mathrm{O}_{3}$ support [11]. These observations further highlight the beneficial combination of $\mathrm{Cu}$ and $\mathrm{Ni}$ also used herein.

The surface modification of $\mathrm{Cu}$ or $\mathrm{CuNi}$ catalysts have been reported in the literature. Gong et al. [64] have reported the modification of active carbon in the $\mathrm{Cu} / \mathrm{AC}$ catalyst by the grafting of sulfonate groups and reported an increase in the activity. The modification leads to better metal dispersion and smaller particle size and different $\mathrm{CuO}^{+} \mathrm{Cu}^{+} / \mathrm{Cu}^{2+}$ ratios, and thus stronger furfural adsorption [64]. In addition, the formation of TFHA has been reported to depend on the surface modification of the support. $\mathrm{Ni}$ and $\mathrm{CuNi}$ catalysts can facilitate the hydrogenation of furfural to TFHA, but the introduction of basic sites can significantly increase the selectivity [16]. In contrast, the increase in the Lewis acidity has been found to increase the MF selectivity over the $\mathrm{Cu}$ catalyst [16]. Thus, the change in the acid-base characteristics of our CuNi catalysts on ACF after acid washing could partly explain the decrease in the THFA formation and the increase in MF formation.

\section{Conclusion}

In this study, mechanically stable activated carbon foams were demonstrated as catalyst supports for the batch hydrotreatment of furfural $\left(503 \mathrm{~K}, 40 \mathrm{bar} \mathrm{H}_{2}\right)$ to produce 2-methylfuran as the target product. The supports were prepared from commercial tannic acid (S1) and pine bark extracts (S2). For comparison, activated carbon support prepared from spruce sawdust (S3) was used. To enhance the MF selectivity over the catalysts, the prepared activated carbon foams were washed with two acids, i.e., $\mathrm{HNO}_{3}$ or $\mathrm{H}_{2} \mathrm{SO}_{4}$. The pine-bark-extracts-based support exhibited the highest specific surface area and pore volume. In addition, its compressive strength was greater than that of the tannic- 
acid-based support due to the different compositions of raw materials. A high mechanical strength leads to less particle shattering in the reactor. In terms of furfural conversion to MF, several of the tested catalysts exhibited almost $100 \%$ conversion, but the most selective catalysts were $\mathrm{Cu} / \mathrm{Ni}$ supported on pine-bark-extract-based activated carbon foam washed with $\mathrm{HNO}_{3}(48 \%)$ and $\mathrm{Cu} / \mathrm{Ni}$ supported on commercial and spruce-sawdust-based activated carbon (57-61\% selectivity), which exhibited the smallest metal particle sizes. Acid washing led to the increase in the surface oxygen content on the activated carbon foams, thereby resulting in higher MF selectivity. Smaller metal particles were observed on the $\mathrm{HNO}_{3}$-washed support than on the $\mathrm{H}_{2} \mathrm{SO}_{4}$-washed support, which explained the higher activity of the $\mathrm{HNO}_{3}$-washed catalysts. Based on the results, activated carbon foams are suitable catalyst support materials with potential to gain high catalytic activity and selectivity combined with high mechanical strength.

\section{Acknowledgements}

Authors T. Varila and R. Kupila thank the Green Bioraff Solutions Project (EU/Interreg/BotniaAtlantica, 20201508) for funding this research. E. Mäkelä acknowledges the grant obtained from Aalto University. Aalto University BioEconomy infrastructure and Dr. Juha Linnekoski are thanked for providing equipment support.

\section{Appendix A. Supplementary Material}

The following documents are supplementary materials for this article:

\section{References}

[1] D.M. Alonso, S.G. Wettstein, J.A. Dumesic, Green Chem. 15 (2013) 584.

[2] X. Li, P. Jia, T. Wang, ACS Catal. 6 (2016) 7621-7640.

[3] B. V Babu, Biofuels, Bioprod. Biorefining. 2 (2008) 393-414.

[4] M. Balat, G. Ayar, Energy Sources. 27 (2005) 931-940.

[5] H. Mäntyranta, (2014). https://smy.fi/en/artikkeli/use-of-shale-gas-creates-more-space-forlignin/. 
[6] G. Ren, G. Wang, H. Mei, Y. Xu, L. Huang, Chem. Phys. Lett. 703 (2018) 1-7.

[7] D. Stewart, Ind. Crops Prod. 27 (2008) 202-207.

[8] J.-P. Lange, E. van der Heide, J. van Buijtenen, R. Price, ChemSusChem. 5 (2012) 150-166.

[9] K. Yan, G. Wu, T. Lafleur, C. Jarvis, Renew. Sustain. Energy Rev. 38 (2014) 663-676.

[10] S. Sitthisa, T. Sooknoi, Y. Ma, P.B. Balbuena, D.E. Resasco, J. Catal. 277 (2011) 1-13.

[11] Z. Fu, Z. Wang, W. Lin, W. Song, S. Li, Appl. Catal. A Gen. 547 (2017) 248-255.

[12] Z. Fu, Z. Wang, W. Lin, W. Song, Energy Sources, Part A Recover. Util. Environ. Eff. 39 (2017) 1176-1181.

[13] N.S. Date, A.M. Hengne, K.-W. Huang, R.C. Chikate, C. V. Rode, Green Chem. 20 (2018) 2027-2037.

[14] S. Srivastava, G.C. Jadeja, J. Parikh, Chem. Eng. Res. Des. 132 (2018) 313-324.

[15] K. Xiong, W. Wan, J.G. Chen, Surf. Sci. 652 (2016) 91-97.

[16] S. Chen, R. Wojcieszak, F. Dumeignil, E. Marceau, S. Royer, Chem. Rev. 118 (2018) 11023-11117.

[17] Y. Shi, ACS Omega. 4 (2019) 17447-17456.

[18] H.-Y. Zheng, Y.-L. Zhu, B.-T. Teng, Z.-Q. Bai, C.-H. Zhang, H.-W. Xiang, Y.-W. Li, J. Mol. Catal. A Chem. 246 (2006) 18-23.

[19] A. Dandekar, R.T.K. Baker, M.A. Vannice, J. Catal. 184 (1999) 421-439.

[20] R. Rodiansono, M. D. Astuti, T. Hara, N. Ichikuni, S. Shimazu, Green Chem. 21 (2019) 2307-2315.

[21] S. Sitthisa, W. An, D.E. Resasco, J. Catal. 284 (2011) 90-101.

[22] W. Yu, K. Xiong, N. Ji, M.D. Porosoff, J.G. Chen, J. Catal. 317 (2014) 253-262.

[23] M. Ahmedna, W. Marshall, R. Rao, Bioresour. Technol. 71 (2000) 113-123.

[24] M.J. Antal, M. Grønli, Ind. Eng. Chem. Res. 42 (2003) 1619-1640.

[25] B.S. Caglayan, A.E. Aksoylu, J. Hazard. Mater. 252-253 (2013) 19-28.

[26] M. Cox, A.A. Pichugin, E.I. El-Shafey, Q. Appleton, Hydrometallurgy. 78 (2005) 137-144.

[27] J.W. Patrick, Porosity in Carbons: Characterization and Applications, First edit, Wiley, London, 1995.

[28] A. Ahmadpour, D.D. Do, Carbon N. Y. 34 (1996) 471-479.

[29] T. Fu, Z. Li, Chem. Eng. Sci. 135 (2015) 3-20.

[30] A. Mohammad-Khah, R. Ansari, Int. J. ChemTech Res. 1 (2009) 859-864.

[31] W. Gong, C. Chen, H. Zhang, G. Wang, H. Zhao, ChemistrySelect. 2 (2017) 9984-9991.

[32] T. Yamada, K. Tsumuki, US Patent 5685986A, 1997.

[33] G. V Plaksin, O.N. Baklanova, A. V Lavrenov, V.A. Likholobov, Solid Fuel Chem. 48 (2014) 349-355.

[34] A. Amaya, N. Medero, N. Tancredi, H. Silva, C. Deiana, Bioresour. Technol. 98 (2007) 1635-1641.

[35] D. Zhang, P. Fan, D. Wu, Y. Li, China Particuology. 3 (2005) 23-25.

[36] G. Tondi, V. Fierro, A. Pizzi, A. Celzard, Carbon 47 (2009) 1480-1492.

[37] M. Basso, M. Lagel, A. Pizzi, A. Celzard, S. Abdalla, BioResources. 10 (3) (2015) 52155232.

[38] C. Lacoste, M.C. Basso, A. Pizzi, A. Celzard, M.-P. Laborie, Ind. Crops Prod. 73 (2015) 4148.

[39] T. Varila, H. Romar, T. Luukkonen, U. Lassi, AIMS Mater. Sci. 6 (2019) 301-314.

[40] G. Tondi, W. Zhao, A. Pizzi, G. Du, V. Fierro, A. Celzard, Bioresour. Technol. 100 (2009) 5162-5169.

[41] G. Tondi, A. Pizzi, Ind. Crops Prod. 29 (2009) 356-363.

[42] M. Link, C. Kolbitsch, G. Tondi, M. Ebner, S. Wieland, A. Petutschnigg, BioResources. 6 
(2011) 4218-4228.

[43] S. Jaatinen, M. Stekrova, R. Karinen, J. Porous Mater. 25 (2018) 1147-1160.

[44] S. Brunauer, P.H. Emmett, E. Teller, J. Am. Chem. Soc. 60 (1938) 309-319.

[45] N.A. Seaton, J. Walton, N. Quirke, Carbon 27 (1989) 853-861.

[46] C. Lastoskie, K.E. Gubbins, N. Quirke, Langmuir. 9 (1993) 2693-2702.

[47] W.D. Harkins, G. Jura, J. Chem. Phys. 11 (1943) 431-432.

[48] V.A. Hackley, A.B. Stefaniak, J. Nanoparticle Res. 15 (2013) 1742.

[49] E. Mäkelä, R. Lahti, S. Jaatinen, H. Romar, T. Hu, R.L. Puurunen, U. Lassi, R. Karinen, ChemCatChem. 10 (2018) 3269-3283.

[50] J.T. Scanlon, D.E. Willis, J. Chromatogr. Sci. 23 (1985) 333-340.

[51] A.D. Jorgensen, K.C. Picel, V.C. Stamoudis, Anal. Chem. 62 (1990) 683-689.

[52] F. Kapteijn, J. Gascon, T.A. Nijhuis, Catalytic Reaction Engineering, in: U. Hanefeld, L. Lefferts (Eds.), Catal. An Integr. Textb. Students, 963rd ed., Wiley-VCH Verlag GmbH \& Co., Weinheim, Germany, 964, 2008: pp. 221-271.

[53] H.S. Fogler, Elements of chemical reaction engineering, 4th ed, Pearson Education, Inc, 961, Westford, Massachusetts, U.S.A., 1987.

[54] H. Bo, L. Guowei, W. Penghui, Z. Xiang, X. Hongxiang, Processes. 7(3) (2019) 167.

[55] S. Biniak, G. Szymański, J. Siedlewski, A. Świątkowski, Carbon 35 (1997) 1799-1810.

[56] J. Ghijsen, L.H. Tjeng, J. van Elp, H. Eskes, J. Westerink, G.A. Sawatzky, M.T. Czyzyk, Phys. Rev. B. 38 (1988) 11322-11330.

[57] A.P. Grosvenor, M.C. Biesinger, R.S.C. Smart, N.S. McIntyre, Surf. Sci. 600 (2006) 17711779.

[58] K. Kadirvelu, C. Faur-Brasquet, P. Le Cloirec, Langmuir. 16 (2000) 8404-8409.

[59] C. Pradoburguete, J. Catal. 115 (1989) 98-106.

[60] S. Jaatinen, R. Karinen, Top. Catal. 60 (2017) 1473-1481.

[61] N. LI, M. Almarri, X. MA, Q. ZHA, New Carbon Mater. 26 (2011) 470-478.

[62] L. Prati, D. Bergna, A. Villa, P. Spontoni, C.L. Bianchi, T. Hu, H. Romar, U. Lassi, Catal. Today. 301 (2018) 239-243.

[63] S. Sitthisa, D.E. Resasco, Catal. Letters. 141 (2011) 784-791.

[64] W. Gong, C. Chen, Y. Zhang, H. Zhou, H. Wang, H. Zhang, Y. Zhang, G. Wang, H. Zhao, ACS Sustain. Chem. Eng. 5 (2017) 2172-2180.

Figure captions:

Fig. 1. Schematic of the preparation of the skeletal backbone for carbon-foam support materials using either tannic acid or pine bark extracts.

Fig. 2. EFTEM photographs of the unreduced catalyst. a) S1_A1_Cu/Ni, b) S1_A2_Cu/Ni, c) S2_A1_Cu/Ni, d) S2_A2_Cu/Ni, e) S3_Cu/Ni, f) Norit_S_Cu/Ni, g) Norit_A_Cu/Ni. Notably, the scale of the photographs is different.

Fig. 3. Furfural conversion as a function of the batch residence time ( $\tau$ ). a) $\mathrm{CuNi}$ on $\mathrm{ACFs}, \mathrm{b}$ ) $\mathrm{CuNi}$ on acid-washed $\mathrm{ACFs}$, and c) $\mathrm{CuNi}$ on reference materials.

Fig. 4. MF selectivity as a function of the furfural conversion. a) CuNi on ACFs, b) CuNi on acid-washed ACFs, and c) CuNi on reference materials.

Scheme captions:

Scheme 1. a) Proposed reaction scheme for the hydrotreatment of furfural b) and the observed condensation products. 